\title{
ESTUDO PARA AVALIAR A ALIMENTAÇÃO DO PRÉ-ESCOLAR ATRAVÉS DE MÉDIAS DO CONSUMO FAMILIAR*
}

\author{
Rosa Nilda MAZZILLI **
}

RSPU-B/232

\begin{abstract}
Mazzilli, R. N. - Estudo para avaliar a alimentação do pré-escolar através
de médias do consumo familiar. Rev. Saúde públ., S. Paulo, 8:375-89, 1974.

REsumo: Foi verificada a possibilidade de avaliar a ingestão alimentar do pré-escolar, através de médias do consumo familiar obtidas por dois processos. Foi utilizada na pesquisa uma amostra de 54 familias e 85 pré-escolares de $2 \mid-\gamma$ anos de idade, pertencentes a duas cidades paulistas. Os pré-escolares foram divididos em dois grupos, segundo o número de crianças por adulto na familia. Para o levantamento dos dados referentes ao consumo alimentar da familia e individual do pré-escolar, durante 24 horas, foi utilizado o método da pesagem direta dos alimentos combinado com o recordatório. Os resultados da ingestão individual do pré-escolar e das médias obtidas foram comparados na respectiva familia. Ficou evidenciado que é necessária a realizaçāo do inquérito individual para avaliar a ingestão real de nutrientes do pré-escolar. Para estudos de grupos populacionais, entretanto, há possibilidade de se utilizar a média por "equivalente criança" (ME) de proteinas totais e a média por pessoa (MF) de cálcio na estimativa do consumo desses nutrientes dos pré-escolares, qualquer que seja a composição familiar. Para os demais nutrientes os resultados sugerem a utilização da média por pessoa ou da média por "equivalente-criança", segundo a maior ou menor concentração de adultos na familia.
\end{abstract}

UNITERmos: Inquérito alimentar*; Pré-escolar*; Consumo de alimentos (método de avaliação) *.

\section{I N T R O D C $\approx$ O}

Nos países em desenvolvimento, a desnutrição constitui ainda grave problema de saúde pública, atingindo os grupos vulneráveis, em particular os pré-escolares.

A desnutrição é problema de causas múltiplas, entre as quais merecem destaque as que se encontram intimamente relacionadas com a disponibilidade dos alimentos, a renda familiar determinando o poder aquisitivo, o desconhecimento do valor dos alimentos e os hábitos e tabus alimentares, causas estas que incidem diretamente sobre o consumo alimentar das famílias. A influência desses fatores poderá ser maior sobre a criança, a partir do momento em que o leite materno já não for suficiente para atender suas necessidades de crescimento e de desen-

* Resumo da dissertação apresentada no Departamento de Nutrição da Faculdade de Saúde Pública da Universidade de São Paulo, para obtenção do título de "Mestre em Saúde Pública"

** Do Departamento de Nutrição da Faculdade de Saúde Pública da USP - Av. Dr. Arnaldo, 715 - São Paulo, SP - Brasil 
MAZZILLI, R.N. - Estudo para avaliar a alimentação do pré-escolar através de médias do consumo familiar. Rev. Saúde públ., S. Paulo, 8:375-89, 1974.

volvimento ou, ainda, quando ela se vê privada desse alimento, recebendo em seu lugar uma alimentação inadequada. A tendência cada vez maior para o desmame precoce ${ }^{1,15,20,22}$ pode ser outro fator importante no desencadeamento da desnutrição.

$\mathrm{Na}$ maioria dos países tropicais a má nutrição está estreitamente relacionada com o período de desmame. Entretanto, BALDO $^{2}$, em pesquisa sobre a má nutrição protéico-calórica no distrito de São Paulo (1971), não observou essa associação, verificando maior prevalência de má nutrição entre as crianças de 4 a 5 anos de idade.

A desnutrição na infância não se reflete somente no crescimento físico e maturação óssea da criança, mas poderá repercutir também no seu desenvolvimento mental 1, 6, 7, 19 .

E necessário investigar a importância de cada uma dessas causas determinantes do problema nutricional de uma comunidade e assim estabelecer prioridades, a fim de que os programas preventivos da desnutrição infantil e de promoção da saúde em geral atendam às necessidades reais daquela população.

O conhecimento da disponibilidade dos recursos locais, especialmente no que se refere aos alimentos regionais, e o dos padrões culturais constituem aspectos preponderantes para a solução do problema da desnutrição. Sentimos a importância do conhecimento dessas informações, em situações experimentais vividas no campo.

Tivemos oportunidade de observar, através de levantamentos sobre consumo e hábitos alimentares * em comunidades do Vale do Ribeira, que nessa região existe o peixe em abundância e, entretanto, essa fonte de proteína animal não é aproveitada adequadamente. Entre os fatores que interferem no baixo consumo desse alimento está o tabu alimentar impedindo, por exemplo, a ingestão do peixe pelas crianças que tanto se beneficiariam dessa proteína de alto valor biológico.

Os responsáveis pela execução dos programas, de posse dessas informaçôes, estarão mais capacitados para proporem as medidas que serão melhor aceitas pelas mães no sentido de orientação correta para alimentar os filhos, sem onerar o orçamento destinado à compra de alimentos.

Nos últimos vinte anos, os problemas nutricionais têm sido objeto de maior preocupação, o que se evidencia pela intensificação das pesquisas em todo o mundo. A maior parte desses estudos tem investigado o consumo familiar e os hábitos alimentares, sem, entretanto, informar a distribuição dos alimentos entre os componentes da família ${ }^{8,12}$.

É importante o conhecimento do consumo alimentar individual de pré-escolares ou de elementos de outros grupos vulneráveis, pois, é através desse conhecimento que saberemos se estão sendo atendidos seus requerimentos nutricionais. Em relação ao consumo alimentar do pré-escolar, por fatores sociais e culturais ou por preferência individual, a criança pode estar recebendo alimentação insuficiente $e$ inadequada para atender a demanda de seu crescimento e desenvolvimento ${ }^{5,8}$, 12,15 .

As pesquisas sobre consumo individual são menos freqüentes do que aquelas realizadas $e m$ nível familiar, pelos problemas que se apresentam para sua execução, exigindo pessoal melhor treinado e maior investimento financeiro. Ainda, quando se trate de investigar o consumo alimentar de pré-escolares, Flores et al. ${ }^{9}, 10$ recomendam que seja realizado também o estudo concomitante do consumo familiar. Talvez, seja essa a razão pela qual na literatura encontra-se escassa referência a respeito de investigações sobre o consu-

* Inquéritos alimentares em 1968/1969, realizado pelo Departamento de Nutrição da Faculdade de Saúde Pública da USP - dados inéditos. 
MAZZILLI, R.N. - Estudo pa:a avaliar a alimentação do pré-escolar através de médias do consumo familiar. Rev. Saúde públ., S. Paulo, 8:375-89, 1974.

mo alimentar individual de pré-esculares e, principalmente, comparando-o com a média familiar, visando conhecer as diferenças entre a ingestão de alimentos da criança e dos demais elementos da família.

Flores et al. ${ }^{9}$, estudando a dieta da família e do pré-escolar em três comunidades indígenas da Guatemala, durante quatro anos consecutivos, verificaram que a ingestão média de nutrientes entre as crianças apresentou diferenças muito pequenas, não só para as três localidades, como também de ano para ano, com exceção das vitaminas A e C. Quando a ingestão alimentar da criança foi comparada com o consumo médio por pessoa na respectiva família, constataram que ela recebia, aproximadamente, $50 \%$ daquele valor para todos os nutrientes estudados. Esses resultados foram considerados baixos pelos autores, memo quando a ingestão média na família era adequada.

A necessidade de informações sobre o consumo alimentar do pré-escolar e as dificuldades para sua obtenção, sugeriunos o presente estudo, que investiga a possibilidade de se utilizar a média por pessoa e/ou a média por "equivalente-criança", obtidas através do consumo alimentar da família, como estimativa da ingestão da criança. Acreditamos, assim, poder contribuir para melhorar o conhecimento do padrão alimentar do pré-escolar, grupo vulnerável de difícil acesso e, por essa razão, pouco atingido pelos programas de assistência alimentar. Segundo KeVany ${ }^{13}$ o pré-escolar faz parte de um grupo "esquecido no planejamento econômico nacional pela contribuição aparentemente escassa como força produtiva da nação". É preciso lembrar que essa população menor de 5 anos de hoje, cuja proporção chega a cerca de $18 \%$ nas regiōes em desenvolvimento ${ }^{13}$, dentro de alguns anos será a força produtora ativa do país.

É evidente que o conhecimento da ingestão alimentar desse grupo etário, através do consumo familiar, será informação valiosa no planejamento de programas de suplementação alimentar, uma vez que envolve menor investimento de recursos humanos e financeiros do que aqueles exigidos para o inquérito individual.

Atualmente, com a implantação dos Centros de Educação e Alimentação do Pré-escolar (CEAPE) ${ }^{11}$, na cidade de São Paulo e no interior do Estado - programa destinado a prestar assistência e educação alimentar aos pré-escolares, contando com a participação ativa da mãe - será de fundamental importância o conhecimento da ingestão de nutrientes desse grupo etário para que aquele possa atender às reais necessidades nutritivas da criança.

\subsection{Objetivo}

O objetivo proposto foi verificar a possibilidade de utilização da média por pessoa ou da média por "equivalente-criança" do consumo alimentar da família, para estimar a ingestão individual do préescolar, nos inquéritos alimentares de nível familiar.

\section{METODOLOGIA}

\subsection{Descrição da área}

O levantamento foi realizado em amostra da população das cidades paulistas de Getulina e Mirante do Paranapanema, pertencentes às $7 .^{a}$ e $100^{a}$ Regiốes Administrativas da Secretaria de Economia e Planejamento do Estado de São Paulo, respectivamente ${ }^{17,18}$.

Essas comunidades foram as escolhidas, em 1972, para a realização do inquérito alimentar que se destina, primordialmente, ao treinamento dos alunos do Curso de Graduação de Nutricionistas da Faculdade de Saúde Pública da Universidade de São Paulo.

A economia das comunidades estudadas é essencialmente agro-pecuária, sendo seus 
MAZZILLI, R.N. - Estudo para avaliar a alimentação do pré-escolar através de médias do consumo familiar. Rev. Saúde públ., S. Paulo, 8:375-89, 1974.

principais produtos agrícolas o amendoim, feijāo, milho, café e algodão. A pecuária está representada, principalmente, pelo gado de corte e, em menor escala, pelas aves e suínos.

\subsection{Amostra}

Nos municípios de Getulina e de Mirante do Paranapanema havia, em junho de 1972, respectivamente, 835 e 1015 famílias, perfazendo um total de $1850^{*}$. Tomando cada município como um estrato, destas 1850 foi sorteada uma amostra casual estratificada com partilha igual composta de 168 famílias. Destas, foram excluídas aquelas famílias que não tinham crianças de $2 \mid-7$ anos, restando 54 famílias que contavam com crianças nesse grupo etário, num total de 85 pré-escolares. Desta forma, a nossa amostra representa uma sub-amostra da que foi utilizada para o inquérito alimentar. A distribuição dessas famílias, segundo o número de crianças por família está na Tabela 1 .

TABEA 1

Distribuição de frequiencias das 54 fámílias. segundo o número de crianças de $2 \mid-7$ anos na familia

\begin{tabular}{c|c|c|c}
\hline $\begin{array}{c}\text { Número de } \\
\text { crianças de } \\
2 \mid-7 \text { anos } \\
\text { na famillia }\end{array}$ & $\begin{array}{c}\text { Número } \\
\text { de } \\
\text { crianças }\end{array}$ & $\begin{array}{c}\text { Número } \\
\text { de } \\
\text { familias }\end{array}$ & $\%$ \\
\hline \hline 1 & 30 & 30 & 56 \\
2 & 34 & 17 & 31 \\
3 & 21 & 7 & 13 \\
\hline Total & 85 & 54 & 100 \\
\hline
\end{tabular}

Apresentando as famílias em estudo, composição muito variada quanto à proporção entre o número de pré-escolares e o de adultos, julgamos de interesse dividir as 85 crianças amostradas em dois grupos, segundo a relação criança/adulto **, para verificar se o número de adultos na família poderia influir sobre as médias por pessoa e por "equivalente-criança", quando comparadas com o consumo individual do pré-escolar.

Para determinar o valor da relação criança/adulto, correspondente a cada família, considerou-se como criança todos os elementos de $0-7$ anos de idade $e$ como adulto, os elementos de 7 anos $e$ mais da família.

Para a divisão dos pré-escolares em 2 grupos, considerou-se a distribuição de freqüência das 85 crianças, conforme o valor da relação criança/adulto na família, apresentada na Tabela 2.

TABELA 2

Distribuição de freqüèncias das 85 crianças, segundo a relação criança/adulto na familia

\begin{tabular}{|c|c|c|}
\hline \multicolumn{2}{|c|}{ Relação na família } & \multirow{2}{*}{$\begin{array}{l}\text { Fre- } \\
\text { qüência }\end{array}$} \\
\hline $\begin{array}{l}\text { N.o de adultos } \\
\text { criança }\end{array}$ & $\begin{array}{l}15.0^{\circ} \text { de crianças } \\
\text { adulto }\end{array}$ & \\
\hline 1 ou menos & 1 a 2 & 12 \\
\hline+1 a 2 & 0,75 a 0,50 & 29 \\
\hline+2 a 3 & 0,44 a 0,33 & 22 \\
\hline+3 a 4 & 0,30 a 0,25 & 11 \\
\hline+4 a 5 & 0,22 a 0,20 & 5 \\
\hline$+5 a 6$ & 0,17 & 1 \\
\hline+6 a 7 & 0,14 & 2 \\
\hline+7 a 8 & 0,12 & 3 \\
\hline Total & & 85 \\
\hline
\end{tabular}

Determinando-se a mediana da distribuição encontrou-se o valor $\mathrm{Md}=0,44$

* Da relação destas familias foram excluídas aquelas cujos componentes participavam de refeições em bares, bem como aquelas residentes em hotéis e pensões.

* A relação criança/adulto, na família, significa o total de crianças para o total de adultos na familia. 
MAZZILLI, R.N. - Estudo para avaliar a alimentação do pré-escolar através de médias do consumo familiar. Rev. Saúde públ., S. Paulo, 8:375-89, 1974.

(correspondente a uma criança/2 $1 / 4$ adultos), o qual foi adotado como valor divisório para a formação dos 2 grupos das 85 crianças. Assim procedendo, ficaram no grupo 1 todas as crianças, cujas famílias tiveram a relação criança/adulto <
0,50 ; e, no grupo 2 , aquelas em cujas famílias essa relação foi $\geqslant 0,50$.

Distribuindo-se as 85 crianças pertencentes às 54 famílias, de acordo com a relação criança/adulto na família à qual pertenciam, obtivemos a Tabela 3 .

TAB ELA 3

Número de familias e número de crianças, segundo o total de crianças na familia e a relação criança/adulto

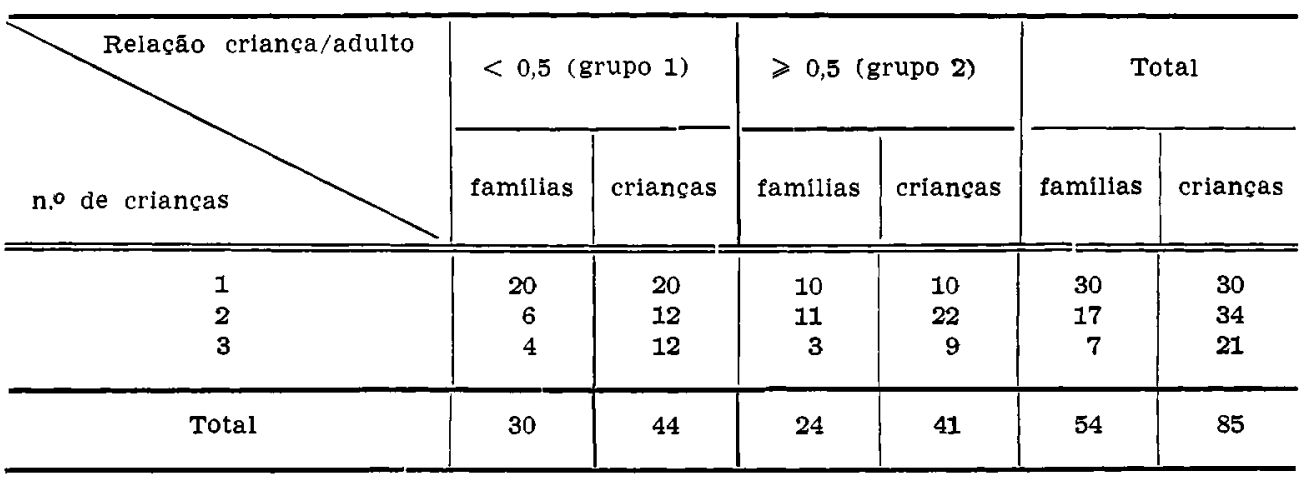

\subsection{Método}

Para se atingir o objetivo proposto foram utilizadas a média por pessoa e a média por "equivalente-criança", bem como a ingestão individual do pré-escolar, obtidas através de levantamento dos dados referentes à quantidade dos alimentos ingeridos por crianças de $2 \mid-7$ anos de idade e respectivas famílias.

Empregou-se, na coleta dos dados, o método da pesagem direta combinado com o recordatório, em entrevista com a mãe ou a pessoa responsável pelo preparo e distribuição dos alimentos na família.

Cada família foi visitada durante dois dias consecutivos para se conhecer o consumo alimentar de 24 horas. As quantidades dos alimentos foram obtidas por pesagem direta e estimativa das medidas caseiras, registrando-se, simultaneamente, o consumo da família e da criança.
Os dados foram coletados por alunos do 3. ${ }^{\circ}$ ano do Curso de Graduação de Nutricionistas, no período de 9 a 22 de outubro de 1972, durante o inquérito alimentar em nível familiar, já referido. Esses alunos foram submetidos a treinamento especial, visando padronizar a entrevista e o registro das informações. Nessa ocasião tomaram conhecimento do objetivo da investigação e foram alertados sobre a importância da precisão e fidedignidade dos dados a serem obtidos. Durante o levantamento houve supervisão direta e contínua dos agentes de campo, sendo realizadas reuniōes diárias para dirimir as eventuais dúvidas surgidas nas entrevistas ou no registro das informaçōes.

Para o cálculo da ingestão de nutrientes da família e da criança foi utilizada a Tabela de Composição Química dos Alimentos ${ }^{21}$. Os dados obtidos foram codificados no Centro de Computação Eletrônica da Universidade de São Paulo. 
MAZZILLI, R.N. - Estudo para avaliar a alimentação do pré-escolar através de médias do consumo famlliar. Rev. Saúde públ., S. Paulo, 8:375-89, 1974.

Para alcançarmos o nosso objetivo, além do consumo individual da criança $(\mathrm{CR})$, obtivemos dois tipos de média, baseados no consumo alimentar da família: a média por pessoa e a média por "equivalente-criança". A média por pessoa (MF) é o resultado da divisão da quantidade total de cada alimento consumido na família pelo número de seus componentes, levando-se em conta a presença dos mesmos às refeições do dia, bem como o valor atribuído a cada refeição ${ }^{16}$. A média por "equivalente-criança" (ME) é o resultado da divisão da quantidade total de cada alimento consumido na família pela soma de seus componentes familiares em termos de "equivalente-criança", considerando-se a presença dos mesmos às refeições do dia e o valor de cada refeição. Adotamos como "equivalente-criança" os valores de $1 / 2$ a uma unidade, dependendo da idade do pré-escolar investigado, segundo os dados apresentados na Tabela 4. Para a elaboração desta Tabela, FLores et al. * basearam-se nos requerimentos nutricionais da FAO (Food Agriculture Organization) estabelecidos para o "homem e a mulher de referência", considerando, "em parte as necessidades fisiológicas do indivi- duo". Assim, atribuindo-se os valores correspondentes aos elementos de cada família, determinamos a soma dos "equivalentes-criança" da família. Dividindo-se a quantidade total de alimentos consumidos na família pela soma dos "equivalentes-criança" obtivemos a ingestão alimentar da criança. Utilizando a Tabela de Composição Química dos Alimentos ${ }^{21}$ chegamos à $M E$ ou à $M F$ de calorias e de nutrientes de cada pré-escolar.

\subsection{Material}

2.4.1. Balanças: Para a pesagem dos alimentos foram usados dois tipos de balanças:

1. pesa-cartas, adaptado para pesos de alimentos, capacidade máxima $500 \mathrm{~g}$ e divisões de 10/10 g;

2. doméstico, com mola, capacidade máxima $2 \mathrm{~kg}$ e divisões de $50 / 50 \mathrm{~g}$.

2.4.2. Medida volumétrica: Para obter o volume das medidas e utensílios caseiros, empregamos a medida volumétrica, de plástico, capacidade de $1.000 \mathrm{ml} \mathrm{e}$ graduação de $50 / 50 \mathrm{ml}$.

TABELA 4

Distribuição proporcional dos alimentos na familla

\begin{tabular}{|c|c|}
\hline $\begin{array}{c}\text { Classe de individuos conforme a idade, o sexo e } \\
\text { o estado fisiológico }\end{array}$ & "equivalente-criança" \\
\hline 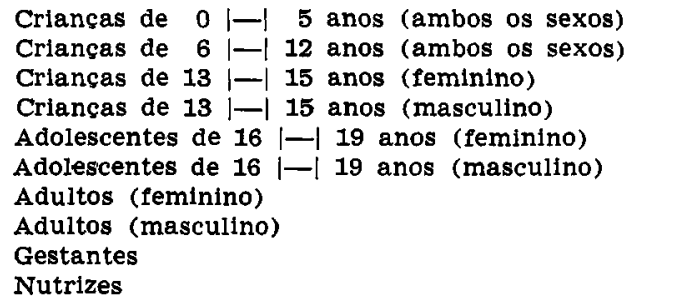 & $\begin{aligned} 1 / 2 & \text { unidade } \\
1 & \text { unidade } \\
1 & \text { unidade } \\
11 / 2 & \text { unidades } \\
1 & \text { unidade } \\
2 & \text { unidades } \\
1 & \text { unidade } \\
2 & \text { unidades } \\
1 & \text { unidade } \\
2 & \text { unidades }\end{aligned}$ \\
\hline
\end{tabular}

Fonte: Comunicação pessoal de M. Flores e colaboradores, do Instituto de Nutrición de Centro América y Panama.

* Comunicação pessoal. 
MAZZILLI, R.N. - Estudo para avaliar a alimentação do pré-escolar através de médias do consumo familiar. Rev. Saúde públ., S. Paulo, 8:375-89, 1974.

2.4.3. Formulärio: Para o registro dos dados sobre o consumo alimentar da família e da criança, utilizou-se formulário apropriado.

\subsection{Tratamento estatístico}

Para a análise estatística dos resultados foram considerados dois grupos:

Grupo 1: constituído pela totalidade de crianças de $2 \mid-7$ anos de idade e pertencentes a famílias onde, para cada criança, o número de adultos é maior que 2 (relação criança/adulto $<0,50$ ).

Grupo 2: constituido pela totalidade de crianças de $2 \mid-7$ anos de idade e pertencentes a famílias onde, para cada criança, o número de adultos é igual ou menor que 2 (relação criança/adulto $\geqslant$ $0,50)$.

Para atender ao objetivo do trabalho compararam-se os resultados das médias por pessoa e por "equivalente-criança" com o consumo individual da criança, referentes a calorias e seis nutrientes: proteínas (totais e de origem animal), cálcio, vitaminas $A, B_{1}, B_{2}$ e $C$. Nesse sentido, foram realizados testes de significância, de comparação entre médias de duas populações correlatas ${ }^{3}$. Tentou-se, ainda, verificar a existência de uma relação entre a média por pessoa na família e o consumo individual da criança, estudando-se as correlações entre essas variáveis e o tipo de regressão, descrevendo a relação entre as mesmas. Para tanto, foram realizados testes dos coeficientes de correlação ${ }^{14}$ e testes de linearidade e de horizontalidade ${ }^{4}$.

\section{RESULTADOS E COMENTARIOS}

Os resultados do consumo individual (CR) e das médias por pessoa (MF) e por "equivalente-criança" (ME), referenles à amostra dos grupos 1 e 2, são apresentados nas Tabelas 5 e 6 .

\subsection{Testes de significância}

Para cada criança temos os valores de calorias e de nutrientes avaliados pelos três métodos.

Para verificar qual das duas médias ( $\mathrm{FF}$ ou ME) pode ser utilizada na avaliação do consumo individual (CR) da criança, realizamos a primeira série de testes de significância de comparação entre médias de duas populações correlatas.

Para ambos os grupos, testou-se a hipótese de que a totalidade dos valores que representam a diferença absoluta entre $\mathrm{ME}$ e o $\mathrm{CR}$ e entre a MF e o CR têm a mesma média, contra a hipótese alternativa de que a primeira diferença $\mid$ ME-CR | tem média menor do que a segunda $\mid$ MF-CR |.

Os resultados dos testes de significância mostraram que, em média, o erro será menor quando se utilizar a ME para a avaliação do consumo de calorias e de proteínas totais da criança, independentemente da concentração de adultos na família. Entretanto, para os demais nutrientes estudados, com exceção da vitamina $B_{1}$ do grupo 1 , pode-se concluir que, em média, o erro será o mesmo, qualquer que seja o processo (ME ou MF) usado na avaliação do consumo de nutrientes de crianças desse grupo etário.

Para completar nosso estudo procuramos saber, primeiramente, se a ME pode ser considerada equivalente ao $\mathrm{CR}$ de calorias e de nutrientes da criança. Com essa finalidade realizamos a segunda série de testes de significância, de comparação entre médias de duas populações correlatas. Portanto, para as calorias e para cada um dos nutrientes foi testada, para os grupos 1 e 2, a hipótese de que a distribuição dos valores da $\mathrm{ME}$ e a distribuição dos valores do CR têm médias iguais, contra a hipótese alternativa de que essas médias sejam diferentes.

Pelos resultados dos testes aplicados, chegou-se à conclusão que há possibilidade de se utilizar: 


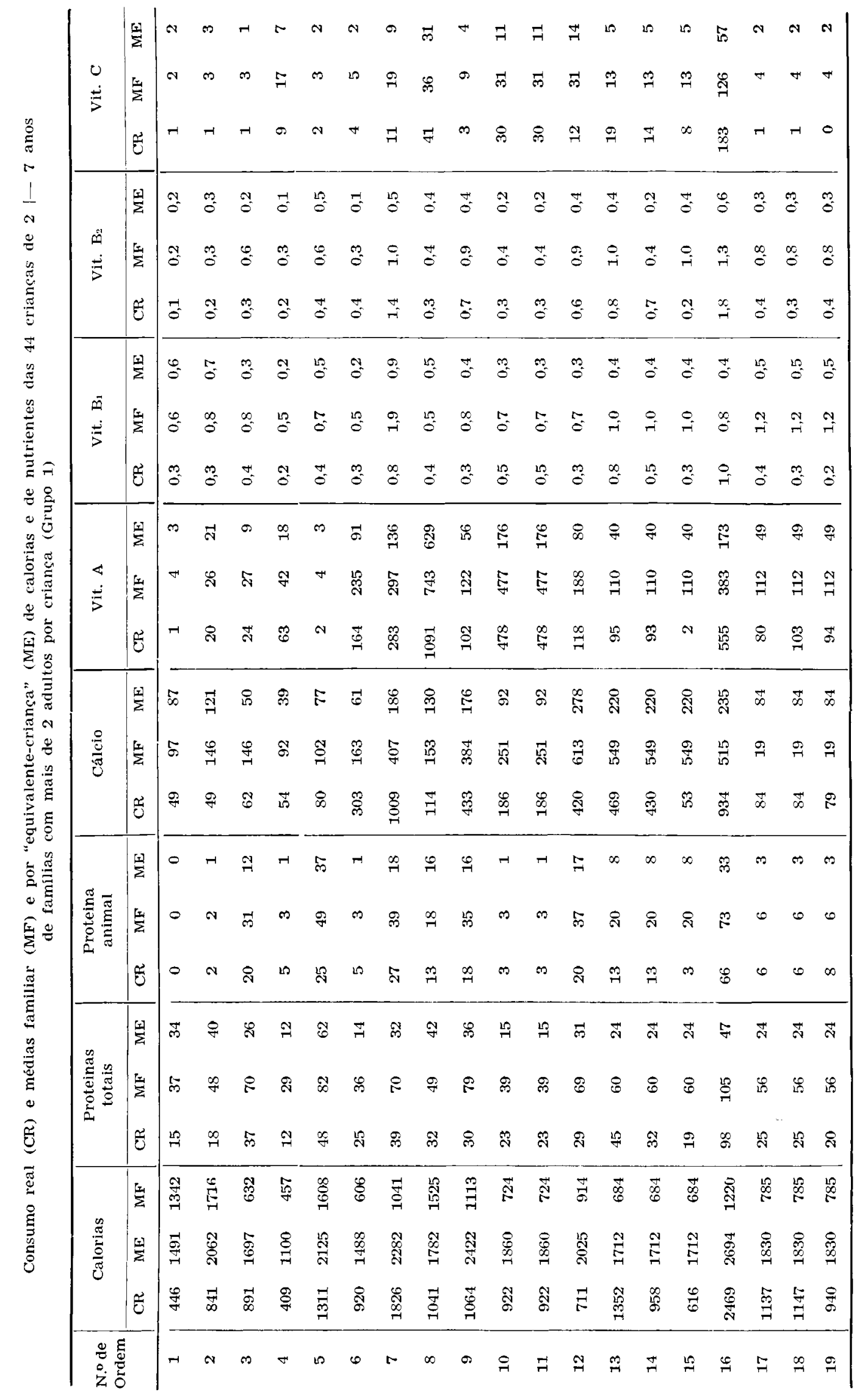




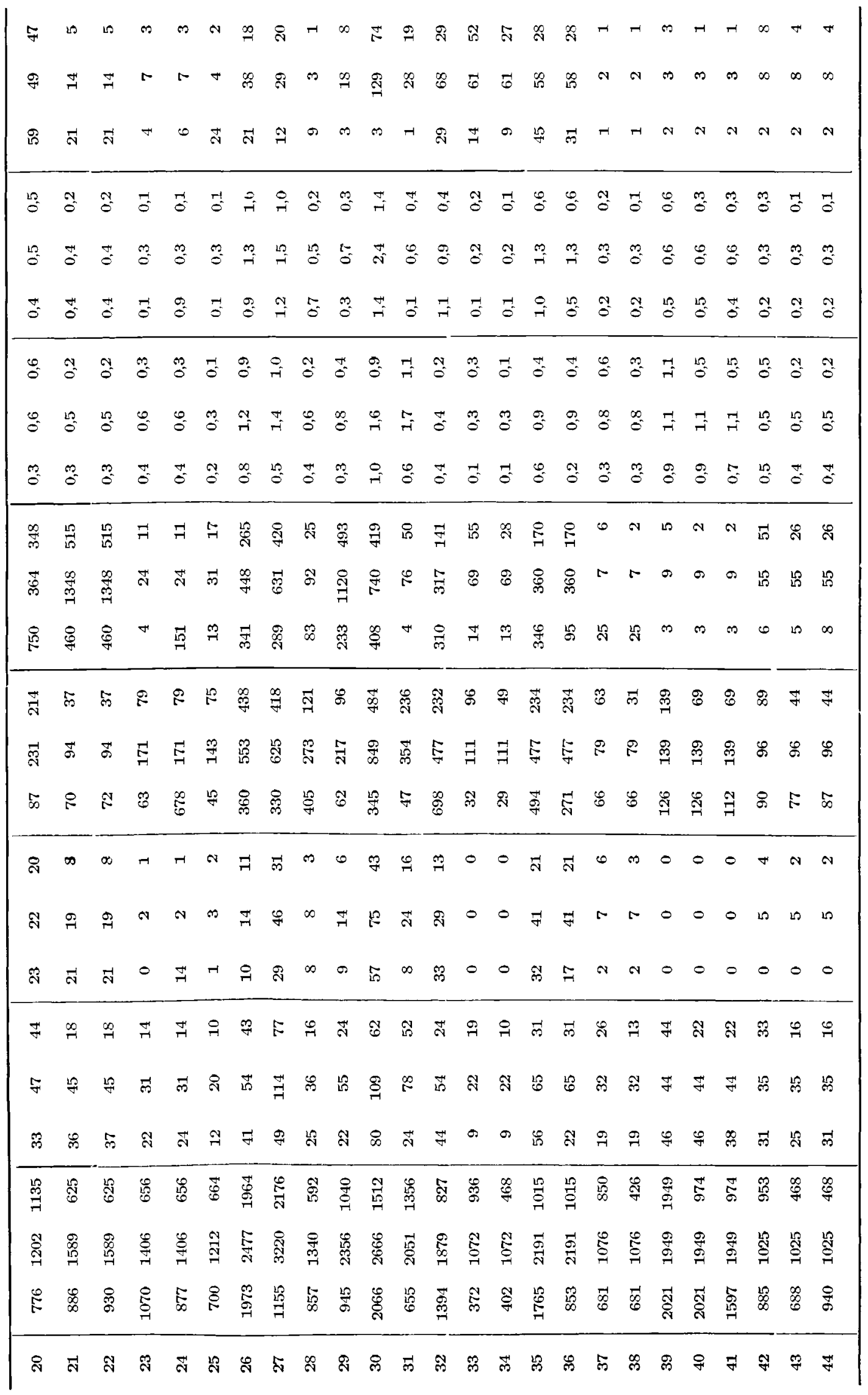




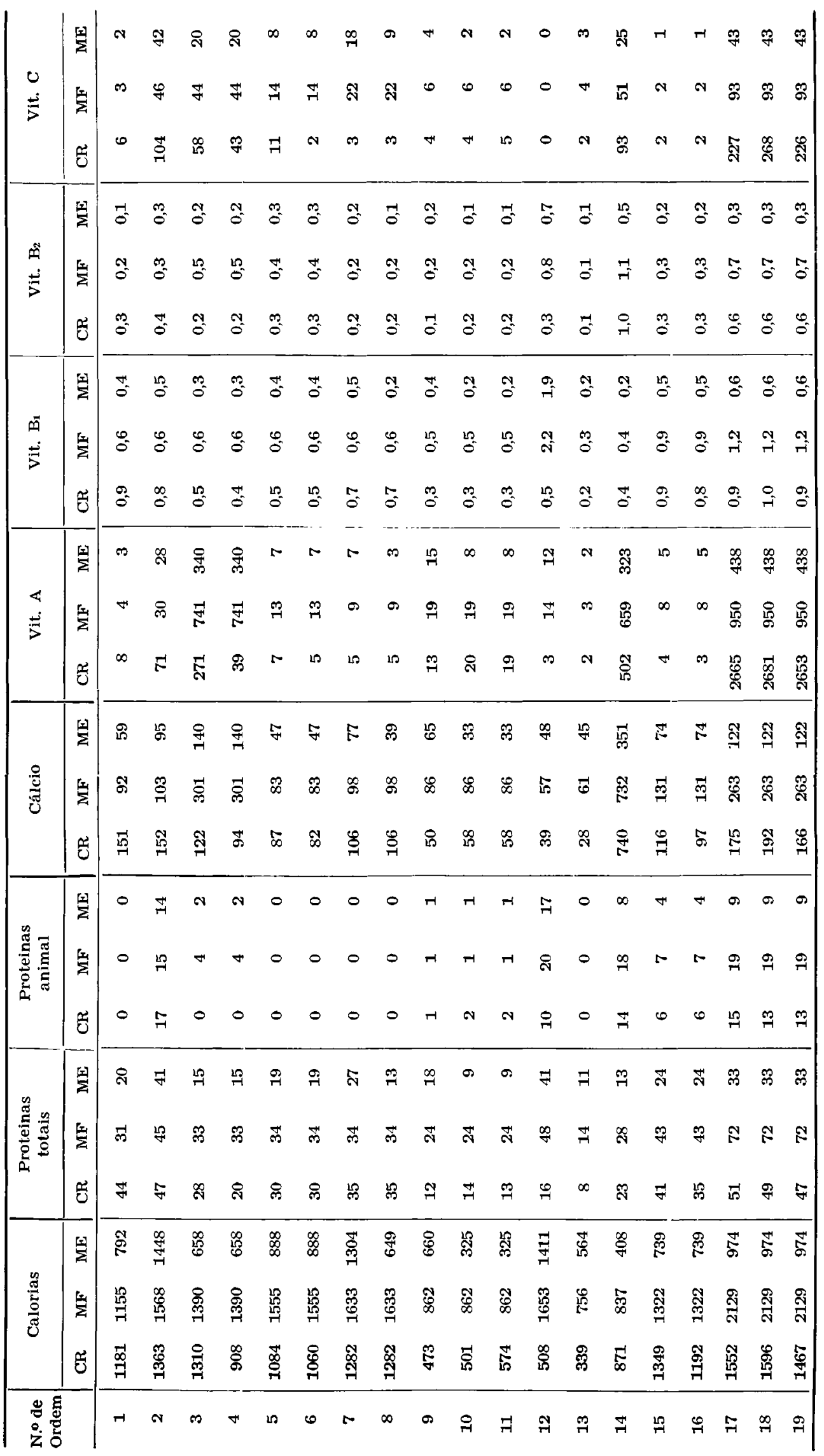




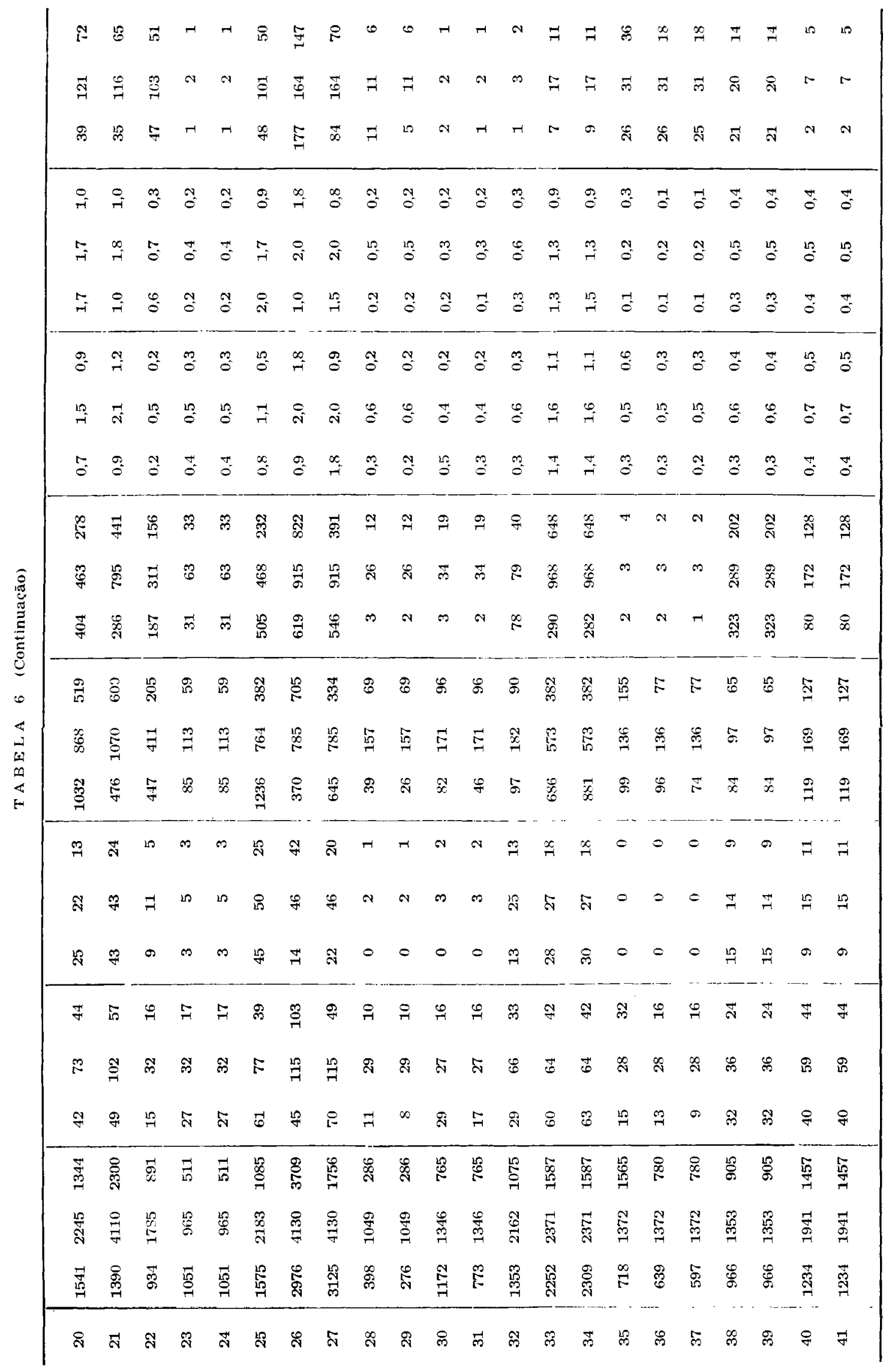


MAZZILLI, R.N. - Estudo para avaliar a alimentação do pré-escolar através de médias do consumo familiar. Rev. Saúde pübl., S. Paulo, 8:375-89, 1974.

- a ME de calorias, de proteína animal e de vitaminas $A$ e $C$, para avaliar o CR médio desses nutrientes no grupo de pré-escolares, em cujas famílias havia mais de 2 adultos para cada criança (relação criança/adulto $<0,50$ );

- a MF das vitaminas A e C na avaliação do CR médio para esses nutrientes, em cujas famílias havia 2 ou menos adultos para cada criança (relação criança/adulto $\geqslant 0,50$ );

- a ME de proteinas totais e de vitamina $B_{1}$, independentemente da composição familiar;

- a MF de cálcio, independentemente da composição familiar.

Ao analisarmos conjuntamente os dados obtidos nos testes de significância aplicados para verificar qual o tipo de média do consumo alimentar (ME ou MF) está mais próximo do consumo real (CR) da criança e ou se a média por "equivalente-criança" pode ser considerada comparável ao $\mathrm{CR}$, fomos levados a aceitar que a média das médias por "equivalente-criança" (ME) de proteínas totais pode ser considerada igual à média do consumo real (CR) de proteínas totais, para o grupo etário de $2 \mid-7$ anos.

Pelo exposto, verificamos que não é aconselhável o emprego da ME na avaliação do CR de proteínas totais nos estudos em que há necessidade de se conhecer, com maior precisão, o consumo individual nesse grupo etário. Entretanto, para os estudos populacionais a ME pode ser utilizada para avaliar o CR médio de proteínas totais de pré-escolares.

Não sendo recomendável nenhum tipo de média do consumo alimentar da família para avaliar a ingestão individual de nutrientes do pré-escolar, tentamos encontrar uma relação através da qual, conhecendo-se a média por pessoa na família (MF), nos fosse possível estimar o consumo individual da criança dentro da respectiva família. Demos preferência à MF por ser a média obtida por metodo- logia já padronizada, internacionalmente recomendada e usada para a apuração dos inquéritos alimentares, permitindo a comparabilidade dos resultados de levantamentos nas diferentes áreas ou regiōes. A ME já foi obtida empregando-se os dados da Tabela 4, propostos pelos autores para complementação das informações nos inquéritos individuais e não é utilizada habitualmente para avaliar a ingestão total de nutrientes. Nesse aspecto, nosso objetivo foi encontrar uma metodologia de mais fácil aplicação, utilizando dados dos quais já se tem disponibilidade.

A relação que nos propusemos encontrar seria dada por uma expressão que exigiu a aplicação de uma série de testes, com determinada seqüência. Primeiramente, realizamos o teste do coeficiente de correlação entre as duas variáveis (CR e MF) para os grupos 1 e 2. Os resultados do teste permitiram aceitar a correlação entre a MF e o CR de todos os nutrientes, com exceção da proteína animal em ambos os grupos e da vitamina $\mathrm{C}$, no grupo 2.

A seguir, para os nutrientes cuja correlação foi aceita, procurou-se uma expressão relacionando as variáveis $M F$ e CR. Inicialmente foi estimada a reta de regressão da variável $C R$ na variável MF. Testou-se a linearidade, a qual foi aceita apenas para cálcio e vitaminas $B_{1}$ e $B_{2}$ do grupo 1. Para estes nutrientes, nesse grupo, aplicou-se o teste de horizontalidade, o qual não foi aceito para nenhum deles, obtendo-se a reta de regressão estimada e as expressões dos limites do intervalo de confiança de $95 \%$ para o valor de CR correspondente a um valor de MF. Obtivemos, ainda, o intervalo de confiança na previsão de um valor de CR para a MF igual ao valor médio das $\mathrm{MF}$ da amostra nos grupos 1 e 2.

Para os nutrientes em que não se aceitou a linearidade da regressão do $\mathrm{CR}$ em $\mathrm{MF}$, foi aplicado um teste de regressão a fim de se verificar se aceitaríamos uma curva exponencial que descrevesse a re- 
MAZZILLI, R.N. - Estudo para avaliar a alimentaçåo do pré-escolar através de médias do consumo famlliar. Rev. Saúde puibl., S. Paulo, 8:375-89, 1974.

lação entre essas duas variáveis. Tal hipótese foi também rejeitada para todos os casos.

Nos casos para os quais foi aceita a linearidade dessa regressão, cálcio e vitaminas $B_{1}$ e $B_{2}$ do grupo 1 , ainda assim, verificamos, com uma confiança de $95 \%$, que o intervalo para a estimativa do CR dada a MF foi muito grande. Uma amplitude tão elevada do intervalo não recomenda a sua aplicação na estimativa do consumo individual do pré-escolar.

Revendo a literatura a respeito do consumo alimentar individual da criança, relacionando-o com a ingestão média na família, não encontramos nenhum estudo que nos permitisse comparação com os nossos resultados. Estudo semelhante a este, aplicando teste de coeficiente de correlação, foi realizado por FLoRes et al. ${ }^{10}$ em uma área rural da Guatemala, mas empregando a porcentagem de adequação dos nutrientes da família e da criança, enquanto nós utilizamos o consumo dos mesmos.

Acreditamos que os resultados por nós encontrados estejam influenciados pela grande variabilidade do tipo de alimentação dado às crianças, uma vez que o grupo etário investigado abrangeu cinco faixas de idade, isto é, pré-escolares de 2 - 7 anos.

Analisando os formulários observamos que aquelas famílias que podiam adquirir alimentos mais apropriados para as crianças, como o leite e as frutas, destinavam estes a 1 ou 2 crianças mais novas, mesmo que na família houvesse outros pré-escolares para os quais os alimentos mencionados são de importância fundamental. Em outras famílias, mesmo as crianças de um ano não recebiam o leite, tendo alimentação igual à dos adultos. Nesses casos, o baixo poder aquisitivo determinou o tipo de alimentaçáo da criança, embora a mãe estivesse consciente das necessidades alimentares de seus filhos. Assim verificamos que, conforme a possibilidade econômica da família, a alimentação das crianças de 2 e 3 anos, de modo geral, recebia maior atenção por parte da mãe do que a alimentação daquelas em idades superiores, fato esse também observado por BALDo 2. Desta forma, podemos atribuir a essas observaçóes a falta de correlação entre o $\mathrm{CR}$ e a MF para proteina animal nos dois grupos e vitamina $\mathrm{C}$, no grupo 2, por serem as frutas e o leite os maiores veiculadores desses nutrientes na alimentação da criança.

$A$ análise dos resultados evidencia aspectos a serem esclarecidos, o que somente será possível através da repetição de pesquisas semelhantes, utilizando amostras maiores, estratificadas segundo a composição familiar e as diferentes faixas de idade desse grupo etário.

Sugerimos que em investigações como esta, as entrevistas para a coleta de informaçōes sejam réalizadas no mesmo dia, isto é, duas visitas diárias para a obtenção do consumo alimentar de 24 horas das crianças. Assim, essas informações serão obtidas na hora da refeição ou logo após, o que propiciará maior veracidade dos dados, principalmente nas famílias que contam com mais de um pré-escolar.

\section{CON C L U SOE S}

Do estudo para avaliar o consumo alimentar individual de crianças de $2 /-7$ anos de idade, através de dois processos de obtenção de média na família, chegamos às seguintes conclusões:

1 - Para estudos populacionais há possibilidade de se usar a média por "equivalente-criança" (ME) na estimativa do consumo médio de proteínas totais de pré-escolares, qualquer que seja a composição familiar.

2 - A ingestão rea: de nutrientes do pré-escolar deve ser avaliada através de inquérito individual.

3 - Para investigações em grupo da população é possível estimar o consumo médio de calorias e de vitamina $C$, através da média por "equivalente-criança", para a faixa etária de $2 \mid-7$ anos, quan- 
MAZZILLI, R.N. - Estudo para avaliar a alimentação do pré-escolar através de médias do consumo familiar. Rev. Saúde pübl., S. Paulo, 8:375-89, 1974.

do a relação criança/adulto for $<0,50$. Para os pré-escolares, cuja relação criança/adulto for $\geqslant 0,50$, é possivel avaliar o consumo médio de proteína animal e do vitamina $A$, através da $M E$.

4 - Para estudos populacionais, há possibilidades de se avaliar o consumo médio das vitaminas $A$ e $C$, através da $\mathrm{MF}$, quando a relaçäo criança/adulto for $\geqslant 0,50$.

5 - A utilização da $\mathrm{ME}$ de proteínas para avaliar a ingestão do grupo de $2 \mid-7$ anos de idade, baseada no consumo familiar, fornecerá informações úteis no planejamento de programas adequados de suplementação protéica aos pré-escolares.

6 - E necessária a realização de outras pesquisas semelhantes para se conhecerem, com maior profundidade, as caracteristicas que envolvem as diferenças alimentares entre os pré-escolares, abrangendo também, se possivel, os de um ano, mas subdivididos em faixas etárias de ano em ano, até 5 anos de idade.

RSPU-B/232

MAzzILLI, R. N. - [A study to avaluate the feeding of the preschool child through the family average intake.1 Rev. Saude publ., S. Paulo, 8:375-89, 1974 .

SUMMARY: The possibility of evaluating the feeding of the preschool child by measuring the family intake averages obtained by two processes was here studied. A sample of 54 families and 85 preschool children aged 2 to $\gamma$ years belonging to two cities of the State of S. Paulo was used. The children were divided into two groups, according to the child/adult relationship in each family. The dietary data refering to the children and families were obtained by applying the record dietary method combined with the recall method during 24 hours. The results of the individual intake of the preschool children and the mean family intake obtained were compared within each family. It was shown that in order to discover the preschool individual intake of nutrients it is necessary to carry out individual dietary surveys. However, for population group studies it is possible to use the average per "equivalent-child" for total proteins and calcium, whatever the family composition. As regards the other nutrients the results suggest the utilization of the family mean or the "equivalent-child", according to the family composition.

UNITERMS: Food*; Preschool children*; School Health*.

\section{REFERENCIAS BIBLIOGRAFICAS}

1. AYKROYD, W.R. - Eliminación de las enfermidades carenciales. Ginebrá, OMS, 1970. (Campaña Mundial contra el Hambre, Estudio basio, 24).

2. BALDO, H.A.P.C.S. - Má nutriço protéico-calórica da criança de 0 -. 5 anos do distrito de São Paulo. São Paulo, 1971. [Tese de doutoramento. Faculdade de Saúde Pública da USP].

3. BERQUO, E. - Bioestatística. Sáo Paulo, Faculdade de Higiene e Saúde
Pública da USP. Departamento de Estatística Aplicada, 1968.

4. BERQUO, E. \& MARQUES, R.M. Análise de variancia. São Paulo, Faculdade de Higiene e Saúde Pública da USP. Departamento de Estatística Aplicada, 1963.

5. COMITE MIXTO FAO/OMS DE EXPERTOS EN NUTRICION. Ginebra, 1970. Octavo informe. Ginebra, OMS, 1972. (Org. Mund. Salud Ser. Inf. Tech.. 477). 
MAZZILLI, R.N. - Estudo para avaliar a alimentação do pré-escolar através de médias do consumo familiar. Rev. Saúde públ., S. Paulo, 8:375-89, 1974.

6. CRAVIOTO, J. - La desnutrición proteicocalórica y el desarrollo psicobiológico del niño. Bol. Ofic. sanit. panamer., 61:285-306, 1966.

7. CRAVIOTO, J. \& DELICARDIE, E.R. Mental performance in school age children. Amer. J. Dis. Child, 120: 404-10, 1970.

8. DECLARACION N.o 3 de PAG: naturaleza y magnitud del problema de las proteinas. Bol. Ofic. sanit. pamer., 73:461-4, 1972.

9. FLORES, M. et al. - Annual pattens of family and children's diet in throc Guatemalan Indian communittics. Brit. J. Nutr., 18:281-93, 1964.

10. FLORES, M. et al, - Relación entre la ingesta de calorias $y$ nutrientes en preescolares y la disponibilidad de alimentos en la familia. Arch. Lat.aner. Nutr., 20:41-58, 1970.

11. GANDRA, Y.R. - Plano para a assistência alimentar do pré-escolar. Centro de Educação e Alimentaçâo do Pré-Escolar (CEAPE). São Pau1o. Faculdade de Saúde Pública, Departamento de Nutriçāo, 1972. [mimeografado].

12. HARTOG, A.P. den - La desigualdäd en la distribuición de los alimentos en el hogar. Notic. Nutr, 10(4):8$18,1972$.

13. KEVANY, ․P. - Problemas de nutrición del niño preescolar en América Latiria. Bol. Ofic. sanit. panamer., 60:282-92, 1966 .

14. MARQUES, R.M. - Elementos de Estatistica. Campinas, Instituto Central de Matemática da Universidade de Campinas. Departamento de Estatística, 1969.
15. ORGANIZACIÓN MUNDIAL DE LA SALUD. Malnutrición $y$ enfermedad. Ginebra, 1963. (Campaña Mundial contra el Hambre, Estudio Basico, 12).

16. REH, E. - Manual para la encuestas alimentarias. Roma, FAO, 1972. (FAO - Estudios sobre nutrición, 18).

17. SAO PAULO (Estado) - Secretaria de Economia e Planejamento. Diagnostico 7.a região administrativa: Bauru. São Paulo, 1972.

18. SAO PAULO (Estado) - Secretaria de Economia e Planejamento. Diagnóstico $10^{a}$ região administrativa: Presidente Prudente, São Paulo, 1972. v. 1 .

19. SCRIMSHAW, N. - La malnutrición, el aprendizaje y la conducta. Bol. Ofic. sanit. panamer., 65:197-209, 1968.

20. U.S. Interdepartmental Committee on Nutrition for National Defense. Northeast Brazil nutrition survey, March-May, 1963. Washington, D.C., 1965.

21. UNIVERSIDADE DE SÃO PAULO. Faculdade de Saúde Pública. Departamento de Nutrição. Tabela de composicão quimica dos alimentos: compilação de várias tabelas nacionais e estrangeiras. Sāo Paulo, 1971. [mimeografado].

22. WATERLOW, J. \& VERGARA, A. Protein malnutrition in Brazil. Roma, FAO, 1965. (FAO - Nutritional Studies, 14).

Recetido para publicação em $9 / 9 / 1974$ Aprovado para publicaça em $4 / 10 / 1974$ 